\title{
Os desafios da heterogeneidade na sala de aula de Educação Musical: uma leitura interdisciplinar das políticas e práticas experimentadas
}

\author{
The challenges of heterogeneity into the Musical \\ Education classroom: an interdisciplinary reading \\ about the policies and the practices experienced
}

\author{
Prof $^{\mathrm{a}}$. Dr ${ }^{\mathrm{a}}$. Celia Maria Haas* \\ Prof. Ms. Oswaldo Luís Mori**
}

\begin{abstract}
Resumo: Esta pesquisa procura discutir, refletir e compreender as práticas pedagógicas numa sala de aula de educação musical, desafiada pela heterogeneidade dos alunos do Centro de Estudos Musicais Tom Jobim, de São Paulo - Brasil. Esta diferença foi classificada em três categorias: alunos musicalmente talentosos; alunos que vêm à escola para aprender música; e aqueles com dificuldades no aprendizado musical. Para conhecer a referida instituição foram analisados os Decretos que a criaram, destacando as três gestões pedagógicas, no período de 1994 a 2003, pois cada uma delas demandou mudanças nas práticas do professor. O estudo apoia-se também na descrição da própria história de vida, realçando as práticas desenvolvidas cotidianamente no enfrentamento dos desafios postos pelas diferenças entre os alunos e demandas das diferentes propostas pedagógicas de cada gestão e nas contribuições da Educação Musical (KOELLREUTTER, 1990) e da Interdisciplinaridade (FAZENDA, 2002). As conclusões apontam para as vantagens, em salas heterogêneas, de projetos musicais conjuntos, nos quais cada aluno contribui com seus recursos e possibilidades, ultrapassando a formação musical, preparando-os para uma escuta sensível à cultura em geral.
\end{abstract}

Palavras-chave: Educação musical. Formação de professores. Heterogeneidade em sala de aula. Interdisciplinaridade.

Abstract: This research aims to discuss, reflect and understand the pedagogical practices in a
heterogeneous Musical Class at the Tom Jobim Center of Musical Studies, Sao Paulo - Brazil. The
students have been classified into 3 categories: musically talented students; students who go to school
to learn music; and those students with have difficulties to learn music. In order to know the center the
law that established the creation of the center was analyzed, highlighting 3 periods from 1994 to 2003
as each of the periods demanded changes in teachers' practices. The study is based on teachers' life
history descriptions in which they point out the daily practices used to face the challenges in teaching
heterogeneous classes and the different pedagogical proposals imposed by the different pedagogical
management teams and by the contributions from Musical Education (KOELLREUTTER, 1990) and
Interdisciplinarity (FAZENDA, 2002). The analyses point out advantages in having heterogeneous

\footnotetext{
* Doutora em Educação (Currículo) pela Pontifícia Universidade Católica de São Paulo. Docente da Universidade Cidade de São Paulo - UNICID - São Paulo. E-mail: celiamhaas@uol.com.br

** Mestre em Educação pela Universidade Cidade de São Paulo UNICID - São Paulo. Docente das Faculdades Carlos Gomes, Mozarteum, e do Centro de Estudos Musicais Tom Jobim - Universidade Livre de Música (ULM). Email: oswaldomori@uol.com.br.
} 
classes and joint musical projects in which each student contributes with his/her resources and possibilities, which takes them beyond musical education and preparing them to develop sensibility in terms of music and culture.

Keywords: Musical education. Teacher education. Heteregeneous classes. Interdisciplinarity.

\section{Introdução}

A música, presente e atuante no cotidiano de todos, possui um caráter de natureza interdisciplinar, pois lida com as percepções necessárias ao desenvolvimento da escuta, da fala, do canto, da habilidade em tocar instrumentos, da expressão - vocal, gestual, artística, corporal, musical e da vivência do belo -, ampliando o diálogo entre as diferentes matérias escolares.

Assim, ao olhar atentamente para a trajetória profissional de um professor de formação musical, questões relevantes são postas, dentre as quais os desafios estabelecidos pelo ensino da música aos jovens e às crianças, com destaque à construção de um trabalho em grupo que seja prazeroso e disciplinado, para que todos possam conhecer e usufruir dos elementos que constituem a linguagem musical e das possibilidades de trabalhar esteticamente a música num mundo cheio de transformações.

Destaca-se, entretanto, como desafio maior, as questões que envolvem a heterogeneidade da classe, impondo a constante busca de alternativas para facilitar o aprendizado, que, com auxílio da Interdisciplinaridade proposta por Fazenda (1999; 2002) e da Educação Musical de Koellreutter (1990) são encontradas alternativas para uma prática cotidiana refletida.

Portanto, a questão fundamental desta pesquisa é refletir sobre as diferenças identificadas em sala de aula e procurar compreender a heterogeneidade do alunado, encontrando meios para trabalhar suas peculiaridades relativamente ao ensino de música. Para compreender a heterogeneidade nas salas de aula de ensino musical, foram propostas três categorias: crianças com dificuldade no aprendizado musical; crianças que vêm à escola para serem musicalizadas e que nem sempre se encaminham para o estudo posterior da música; e crianças talentosas com grande potencial para continuar seus estudos. Com esse alunado, a investigação debruçou-se sobre a possibilidade de ensinar música para uma classe com tal perfil, pois pretendeu-se verificar como os três tipos de alunos podem, juntos, aprender música e como se processa a musicalização para cada um deles.

Uma vez que a formação musical estudada deu-se em uma instituição específica, entendeu-se de fundamental importância conhecer a referida escola, o Centro de Estudos Musicais Tom Jobim de São Paulo. Assim, para maior clareza da organização institucional focou-se neste estudo, o período de 1994 a 2003, quando três diferentes gestões pedagógicas foram nomeadas, cada qual com características próprias que impuseram constante revisão dos métodos, abordagens e conteúdos ensinados. Portanto, é também objetivo deste estudo conhecer a escola, sua criação e o que oferece no ensino de música popular e erudita, propiciando a reflexão sobre as práticas de ensino musical institucionalmente desenvolvidas. 
Neste contexto, a investigação, seguindo as orientações de Gil (1995), utilizou-se de procedimentos descritivos/exploratórios, buscando desvelar os caminhos construídos na ação docente para compreender a heterogeneidade em sala de aula, precisamente no Centro de Estudos Musicais Tom Jobim, de São Paulo.

Descreveu-se essa escola de música, debruçando-se sobre a prática vivenciada, desde 1994, possibilitando a construção de um modelo de ensino para tratar sobre os arranjos, composições e organizar pequenas orquestras, nas quais os alunos, uma vez por semana, experimentavam as composições, estilos, compondo em grupo, criando obras para que todo o grupo pudesse executar.

Com auxílio das categorias interdisciplinares de diálogo, autonomia, parceria, afetividade e identidade, o cotidiano foi descrito e, com estas, buscou-se compreender o processo em que se verifica o ensino e aprendizagem em sala de aula visando à construção da educação musical, humana e erudita dos três grupos de alunos.

Ao descrever, reler e refletir sobre o próprio processo de formação, as escolhas feitas na tentativa de ser um bom professor, a incerteza da opção, os desafios diários, enfim, ao inteirar-se sobre a própria conduta foi possível descobrir sobre as transformações resultantes, passando de um professor pouco reflexivo e mero repetidor de conteúdos para um professor aberto ao diálogo interdisciplinar, que buscou, a partir de 1994, aperfeiçoar sua pedagogia. Assim, ao investir na escrita da própria história de vida, foi possível problematizar as experiências vividas para, daí, aprofundar as reflexões a respeito do fazer em sala de aula - a docência - e com isso dar resposta às questões propostas para esta investigação.

Reconheceu-se que o modelo estabelecido para o Centro de Estudos Musicais
Tom Jobim possibilitou a constante revisão das práticas pedagógicas para a concretização da formação da sensibilidade musical dos alunos matriculados e, a partir disso, buscou-se compreender, olhando para o cotidiano refletido que, a partir do envolvimento professor-aluno e pela prática coletiva, seria possível construir um ensino teórico menos abstrato e mais condizente com a faixa etária dos aprendizes.

No estudo documental, privilegiou-se o Decreto $n^{\circ}$. 30.551, de 3 de outubro de 1989, que criou a Universidade Livre de Música, e alguns documentos complementares ao decreto citado, visando situar as políticas públicas que permitiram e autorizaram gerir a instituição de ensino musical, bem como os documentos fornecidos pela assessoria de imprensa da escola. Estes têm o propósito de veicular a imagem institucional ao grande público.

A coordenação da instituição, nas três gestões que compreendem o período de 1994 a 2003, foi investigada num esforço descritivo e interpretativo, buscando identificar as mudanças que cada uma delas provocou nas práticas pedagógicas. Observando essas gestões, foi possível verificar a mudança de enfoque que cada uma introduziu e produziu na condução da instituição e, em consequência, no aprendizado dos alunos.

Ao apresentar os métodos de trabalho aplicados, as políticas e práticas adotadas na escola, as mudanças, revisões e contribuições que cada gestão pôde estabelecer, reconheceram-se os resultados das relações estabelecidas entre as decisões da diretoria, a atuação dos coordenadores, professores e demais profissionais. Construiu-se, pois, um rico e profícuo diálogo entre a análise documental, o fazer musical na escola, a história de vida e as práticas pedagógicas na Universidade Livre de Música. 


\section{Educação musical e a interdisciplinaridade}

Tomou-se metáfora para a interdisciplinaridade a orquestra formada por uma variedade de músicos que, efetivamente, dela participam. Cada músico permite com sua voz - seu instrumento - participar da obra que se executa - o projeto - e, deste modo, todos os envolvidos podem usufruir de um conhecimento maior, a obra em si.

Percebeu-se que a interdisciplinaridade e educação musical têm em comum as cinco categorias indicadas por Fazenda (2002, p. 11) como requerimento da prática docente interdisciplinar: diálogo, autonomia, parceria, afetividade e identidade. Vale ressaltar que categoria, de acordo com Abbagnano (2000, p. 123), ganha conotação de "regras convencionais que regem o uso dos conceitos".

A interdisciplinaridade, como a orquestra, possui seus naipes ou famílias que precisam dialogar para que o conhecimento não se perca. A compreensão da interdisciplinaridade permite evidenciar o papel do maestro, por conta de sua coordenação harmoniosa para que todos toquem juntos. Pensou-se, então, na questão da atitude interdisciplinar. Com essa atitude, o maestro estaria se esforçando para encontrar um resultado no qual a prática favorecesse novo conhecimento, resgatando a leitura de uma obra ou reinterpretando-a. Separados esses naipes os parceiros, as disciplinas -, provavelmente, fariam uma música menos rica, pois estariam supondo uma existência solitária e isolada, fragmentando a unidade da peça musical - a execução da obra em pedaços.

Em sua atitude interdisciplinar, o maestro compreende que pode realizar um bom projeto se todos os naipes se esmerarem, dando o melhor de si na execução da obra. Esse regente, comprometido com a educação musical, tem consciência de que a obra não se repete igual e recorre, inevitavelmente, ao diálogo com os músicos, que nas suas individualidades têm muito a contribuir com o todo. Essa atitude, a busca da unidade em constante trabalho de parceria, consiste na conduta indispensável para a realização do trabalho, a essa altura, transformado e modificado pelas reflexões e ações pedagógicas.

Considera-se de extrema importância o aprendizado que leva em conta a afetividade do aluno como algo importante na construção de seu conhecimento. A aceitação e a valorização como ser pensante e senciente traz a possibilidade de ouvir o outro, de considerá-lo e acolhê-lo. Acolhido, o aluno pode crescer no aprendizado, na busca de sua identidade, que reflete sua maneira própria de fazer música.

Outra categoria igualmente importante é a autonomia que, para Fazenda (1999, p. 83), "a autoridade do professor numa sala de aula comum é outorgada; numa sala de aula interdisciplinar, é sempre conquistada, bem como a autonomia do aluno também o é”.

O ensino da música pode desenvolver a criatividade ao aluno. Por criatividade entende-se a possibilidade de desenvolvimento, da sensibilidade de cada aluno que se aflora ao aprender música. Criativo é o aluno que gosta do que faz e não é obrigado por ninguém a fazer música. Participa da aula e busca responder aos desafios, estimulado pelo prazer que se lhe provoca a criatividade, no processo de aprendizagem, ao improvisar e construir melodias, uma vez que possui dentro de si a vivência dos sons, o modelo das escalas, dos ritmos, de seu corpo em movimento, da emissão da voz, do fazer em grupo, do tocar em sintonia com os demais e escutar e responder de maneira participativa àquilo que está sendo ensinado. 
Para haver criatividade, necessita-se de um ambiente favorável em que professor e alunos possam desfrutar, além dos aspectos cognitivos, também das características da personalidade que permitem um comportamento criativo, conforme destaca Wechesler (2001, p. 166):

As características apontadas na literatura que descrevem um professor criativo são: 1) abertura a novas experiências; 2) ousadia; 3) confiança em si mesmo; 4) curiosidade; 5) humor; 6) preferência por arriscar-se; 7) estar apaixonado por sua área de ensino; 8) idealismo; 9) postura de facilitador.

A categoria diálogo é fundamental para que se possa desenvolver a autonomia do aluno. O diálogo ocorre entre os pares: do professor e seus alunos, do professor e seu coordenador, do professor consigo mesmo e com os autores que sustentam seu embasamento teórico e, ainda, o diálogo com todos os que vivem a escola. O diálogo é inerente ao ser humano, ao estar vivo e em convivência.

O diálogo é a base para se criar a boa criticidade, para construir modelos equilibrados na busca da resolução de problemas. Pede a escuta do outro e este concede a oportunidade ao solicitado. Dialogar requer paciência entre os diferentes e traz novos sopros sobre velhas questões. É, portanto, a base que forma a democracia, provoca o exercício da cidadania e com ela o respeito, assegurando o convívio em sociedade.

Outra categoria interdisciplinar considerada das mais importantes para se educar musicalmente é a identidade. É fundamental que o aluno saiba quem ele é e o que pode fazer musicalmente. O professor comprometido deve auxiliar seu aluno para que, a cada dia, ele possa se aperceber, perceber os demais e obtenha um convívio saudável na classe.
É necessário, num projeto interdisciplinar, compreender e respeitar o modo de ser peculiar de cada um e respeitar, também, o caminho que cada indivíduo empreendeu na busca de sua autonomia. É necessário revelar a identidade, ou seja, a marca teórica de cada um. É no ponto de confluência e não na justaposição das diferentes identidades, contudo, que se pode captar a dimensão da interdisciplinaridade (FAZENDA, 1999, p. 68).

Quanto à parceria, esta é a possibilidade de encontrar o outro em sua singularidade, em sua experiência e em seus conceitos (MENÉNDEZ, 2001).

A parceria pede o comprometimento, a confiança e a cooperação. Este tripé resume as condições que, uma vez estabelecidas, propiciam o sucesso das aulas e a efetiva criação, em sala, de espaços de aprendizagem. Para Justina (2001, p. 160) “aprender passa a ser o produto de parcerias e trocas, em um processo ininterrupto que dura toda a vida”.

O diálogo com as categorias citadas permite utilizar, pedagogicamente, os métodos dos diversos pedagogos musicais que desde o final do século XIX preocuparam-se em percorrer novos caminhos para o ensino da música não somente para músicos, mas também para as crianças e jovens em geral.

Tanto na Europa quanto no Brasil, há vários pedagogos que se preocuparam com o ensino da música, sua apreciação, sua linguagem e mesmo sua popularização, portanto, todos podem ter acesso ao conhecimento musical. São bem conhecidas as atuações de Hans-Joachim Koellreutter, Edgar Willems, Zoltan Kodály, Dalcroze, Carl Orff, Suzuki e Villa-Lobos, entre outros.

No que se refere à educação musical, Koellreutter (1990 apud PAZ, 2000, p. 221) afirma haver três premissas ou preceitos 
norteadores de seu método - que é, na verdade, a ausência de método:

a) Não há coisa errada em música a não ser aquilo que não se pode executar; errado é sempre errado relativo a alguma coisa; o errado absoluto, em música, não existe;

b) Não acredite em nada que o professor diz; não acredite em nada que só professores dizem; não acredite em nada que você lê; não acredite em nada que você pensa; em outras palavras, questione sempre; e

c) Pergunte sempre: por quê? Se o professor não puder explicar o porquê, precisa então pensar um pouco!

Ao exercitar o diálogo entre os conhecimentos musicais com a interdisciplinaridade, novas possibilidades para a atuação de professor de música em sala de aula são reconhecidas, pois, como afirma Snyders (1997, p. 135):

Não desejo que o campo musical se feche em si mesmo, quero vivamente que a música intervenha na interdisciplinaridade, mas em condições em que ela possa fazer ressoar a sua 'nota' própria: a aproximação com os outros campos e o trabalho em comum me parecem mais louváveis se contribuírem para a alegria estética e dela participarem. [...] O ensino da música pode dar um impulso exemplar à interdisciplinaridade, fazendo vibrar o belo em áreas escolares cada vez mais extensas.

O diálogo entre a interdisciplinaridade e a educação musical tece uma nova melodia que provoca uma releitura da beleza e propõe outros modos de ensinar e aprender. Recorrendo novamente a Snyders (1997, p. 135), verifica-se que:

Para alguns alunos é a partir talvez da beleza da música, da alegria proporcionada pela beleza musical, tão frequentemente presente em suas vidas de uma outra forma, que chegarão a sentir a beleza na literatura, o misto de beleza e verdade existente na matemática, o misto de beleza e eficácia que há nas ciências e nas técnicas.

É no espaço de uma escola livre de música que as questões da interdisciplinaridade e da educação musical têm contribuído quanto à compreensão das práticas diariamente construídas, e a apropriação do conhecimento resultante é uma condição para a ampliação da reflexão sobre a prática musical significativa dos grupos de alunos heterogêneos com os quais as diferentes gestões buscaram caminhos pedagogicamente ricos e formadores.

\section{A Universidade Livre de Música e o Centro de Estudos Musicais Tom Jobim: formando alunos e ensinando música}

Pelo Decreto $n^{\circ}$. 30.551, de 3 de outubro de 1989, foi criado o Departamento denominado Universidade Livre de Música (ULM), da Secretaria de Estado da Cultura de São Paulo, com a responsabilidade não somente de agrupar corpos musicais, mas também de constituir uma escola de música onde fosse oferecido, gratuitamente, o ensino da música popular e erudita para crianças, jovens e adultos, não se exigindo diplomas para frequentá-la.

Com a edição do Decreto $n^{\circ}$. 46.506, de 21 de janeiro de 2002, a instituição recebeu o nome de Centro de Estudos Musicais Tom Jobim. Um dos fatores que motivaram a decisão é que a escola não era, de fato, uma universidade e, tampouco, estava vinculada ao Ministério da Educação. Ambos os nomes são empregados para se referir à escola, popularmente conhecida. 
Integra a ULM, segundo o Decreto $n^{\circ}$. 30.551, o Centro de Iniciação, que é o Departamento Infanto-Juvenil responsável pela formação musical de crianças a partir de seis anos de idade. Existem também vários corpos profissionais e semiprofissionais que fazem parte da ULM, cujos músicos-professores ensinam seus instrumentos aos alunos inscritos. São eles: Orquestra Jazz Sinfônica e Banda Sinfônica do Estado de São Paulo (corpos profissionais); e Banda Sinfônica Jovem, Sinfônica Jovem Eleazar de Carvalho, Coral do Estado de São Paulo e Orquestra Jovem Tom Jobim (corpos semiprofissionais). Existem ainda os grupos experimentais, integrados pelos alunos dos departamentos infanto-juvenil e adulto.

Quanto às atribuições gerais, a ULM procura promover e difundir a música em todas as suas modalidades, diversidade de gêneros e estilos que nela são ensinados. Muitos alunos podem usufruir desses conhecimentos, desenvolvendo um espírito aberto a todos os gêneros, partilhando de uma educação integrada, não fragmentada, cujo princípio assemelha-se ao que afirma Fazenda (1999, pág. 29), ou seja, "que a interdisciplinaridade é princípio de unificação e não unidade acabada”.

De igual modo, as músicas erudita e popular não se separam, mas constroem com suas linguagens algo maior do saber musical, diluindo fronteiras, tornando-se permeáveis na construção e no processo da educação musical.

A formação musical acontece em áreas específicas e envolve o aprendizado teórico e prático em duas vertentes - música erudita e popular -, que são divididas na seguinte conformidade:

a) Iniciação musical infantil - para crianças de seis e sete anos e a formação musical dos 8 aos 14 anos - busca, por meio de aulas de canto coral, do contato com instrumentos musicais e de noções teóricas, introduzir as crianças no universo do aprendizado musical. Neste departamento, há vários grupos que no decurso de todo o ano realizam apresentações de caráter artístico-pedagógico, representando o Centro de Estudos Musicais (CEM), em escolas, teatros, encontros corais, instrumentais, tanto em São Paulo quanto em outras cidades. Existem vários instrumentos ensinados na prática em conjunto, como, por exemplo, as cordas, seja no ensino erudito (violinos) ou no ensino popular (violão e cavaquinho). O curso de percussão também é ensinado coletivamente;

b) Formação integrada, no Departamento Adulto, para alunos em nível avançado em instrumentos, procurando integrar as duas linguagens básicas da música erudita e popular;

c) Iniciação e formação musical em Canto para iniciantes, em nível médio ou avançado, que busca iniciar e aperfeiçoar cantores, municiando-os teórica e tecnicamente, seja na área Erudita ou Popular; e

d) Iniciação e formação musical em instrumentos, para iniciantes em nível médio ou avançado, que procura iniciar e aperfeiçoar músicos, técnica e teoricamente, em quase todos os instrumentos de uma orquestra ou banda sinfônica, além de atender instrumentos utilizados na música popular, como bateria, guitarra, gaita, teclado etc.

$\mathrm{Na}$ formação, acontecem também os chamados cursos livres, com duração máxima de um semestre, assim como os “workshops”. São complementares e 
auxiliares dos cursos modulares, mas abertos aos alunos de outras instituições e ao público em geral. São bastante concorridas às vagas nesta escola e, ano a ano, aumenta a procura, mas, infelizmente, ela não tem crescido para atender à demanda, apesar de possuir dois núcleos em São Paulo.

\section{Práticas de gestão das três coordenações pedagógicas no departamento infanto-juvenil}

Para compreender as práticas musicais desenvolvidas foi necessário rever as três diferentes gestões da coordenação pedagógica - vivenciadas no Departamento Infanto-Juvenil. Cada gestão trouxe elementos novos e solicitou aos docentes mudanças e adequações nas práticas de sala de aula. Refletindo sobre o Departamento Infanto-Juvenil e rememorando cada gestão, foi possível perceber e compreender como cada uma delas contribuiu na melhoria das práticas, pois, ao tentar solucionar certos impasses, novas e criativas alternativas se construíram e cada uma delas auxiliou as reflexões coletivas sobre o ensino e aprendizagem dos alunos.

Em agosto de 1994, surgiu a primeira coordenação administrativa do Departamento Infanto-Juvenil. Em 1995, tornou-se, também, pedagógica. A coordenadora sugeriu a criação de um grupo de estudos para a confecção de material musical a ser utilizado por toda a equipe, unificando o trabalho para consecução dos objetivos. Houve muita paciência e longa espera para a participação na troca de ideias e materiais, como também resolução dos conteúdos que seriam ensinados em cada nível. Depois de calorosas discussões, houve definição quanto ao desenvolvimento do curso, denominado iniciação musical para crianças entre cinco e sete anos de idade, com duas aulas semanais de linguagem musical e prática Coral.

A formação musical para as crianças entre 8 e 14 anos compreendia a linguagem musical - teoria musical, solfejo, rítmica, jogos musicais, prática de instrumental Orff e pequena percussão - e a prática coral, com canções a duas e três vozes. Foram criados vários grupos vocais e instrumentais, como percussão e ritmos brasileiros.

Um curso paralelo condensado foi criado para crianças que entrassem com a idade acima de oito anos de idade. Frequentaram jovens com 12 e 13 anos que estudaram no Departamento Infanto-Juvenil, adequando-se, então, para aprender música de maneira mais rápida e, sem prejuízo, prosseguir seus estudos no Departamento Adulto.

A primeira gestão durou quatro anos, ou seja, de agosto de 1994 a agosto de 1998, e o grupo trabalhou na construção dos materiais pedagógico-musicais.

Construiu-se um corpo de conhecimentos, o mais abrangente possível. Os materiais utilizados em sala de aula, como livros, instrumentos e fitas cassetes, eram de procedência diversificada, ou seja, brasileira, francesa e de outros países. Em 1998, ao término da gestão, com a saída da coordenadora que se demitiu por motivos políticos e pessoais, veio também à destituição da diretoria.

Houve resistência quanto à segunda coordenação que, imposta pela nova Diretoria, não pareceu, aos docentes, recair sobre a pessoa certa. Era expectativa dos professores a ascensão de um integrante da própria equipe à coordenação. Mas a nova diretoria, órgão colegiado que administra a ULM, que já enfrentava dificuldades pela saída da primeira coordenadora, entendeu que deveria colocar uma pessoa de sua confiança, mesmo estranha à equipe atual. A coordenadora 
que assumia fora professora na escola antes de 1994, sendo desconhecida dos atuais integrantes do corpo de professores.

Em junho de 1998, o plano de trabalho sofreu modificação. As apostilas, um dos projetos da equipe, não foram confeccionadas devido ao corte de despesas. Quanto à coordenação, os professores não se sentiam à vontade, pois viam nela uma imposição e a desconsideração dos esforços que vinham dedicando à instituição.

A segunda gestão estendeu-se de 1998 a 2001. Cada professor tomou a liberdade de seguir seu próprio caminho metodológico. As reuniões eram esporádicas e, quando aconteciam, a participação dos professores era pouco expressiva. Não havia troca de experiências pedagógicas ou de materiais musicais. No entanto, utilizavam-se os referenciais - conteúdo programático - e as apostilas da Formação Musical da gestão anterior como norte para as atividades, porém esse material não era mais distribuído gratuitamente aos alunos.

Entretanto, a segunda coordenadora deixou sua marca, propondo menos teoria e mais ludicidade, por considerar que a criança sendo trabalhada com exercícios lúdicos, ao atingir idade mais avançada, teria condições de resolver os conceitos teóricos, pois já os havia vivenciado musicalmente. Para ela, mesmo a questão da grafia musical era um ponto a se resolver a posteriori. Em sua gestão, ampliou-se o número de grupos especiais, dando oportunidade a um contingente maior de alunos que pôde integrar os grupos e vivenciar mais a música. Notou-se, também, que o desempenho dos professores cresceu nas apresentações de audições, no ano letivo escolar.

Em 2002 teve início a terceira gestão de coordenação pedagógica no CEM - Tom Jobim, com duas coordenadoras-professoras da própria equipe, convidadas pela direção.
A mesma direção que impôs a segunda coordenação, agora, democraticamente, convidou duas docentes da equipe. Isso aconteceu porque a diretora, passados os acontecimentos da substituição da primeira pela segunda gestão, pôde ver o time formado pelos professores do Departamento Infanto-Juvenil, que ganharam a confiança e credibilidade pelas ações e resultados apresentados nas audições e no trabalho realizado com os alunos.

Nessa terceira gestão, as duas coordenadoras passaram a atuar em conjunto, uma cuidando da parte pedagógico-musical e a outra das questões administrativas. Redimensionaram-se os cursos oferecidos e as apostilas voltaram a ser montadas e aperfeiçoadas, graças às experiências vividas pelos professores nas duas últimas gestões. As questões de avaliação e registro de matérias foram também aperfeiçoadas, assim como novos grupos musicais foram ampliados graças à segunda coordenação.

O grupo manteve-se atento para o que foi realizado na primeira e na segunda administração, ampliando o compromisso e o espaço de atuação do professor na terceira gestão. Restou, pois, comprovado que o movimento, a mudança e um novo olhar são necessários para ponderar e construir com parceria, autoconhecimento, amor, depuração e ação, comprometidos com o novo momento.

\section{Práticas de ensino musical interdisciplinar construídas em salas heterogêneas}

Desde 1994, observou-se a seguinte demanda na procura pelas vagas no Departamento Infanto-juvenil: alunos apaixonados para aprender um instrumento e música em geral, que, provavelmente, serão músicos 
profissionais; alunos que passaram pelo processo de musicalização, mas que não deram continuidade aos estudos musicais, interrompendo o aprendizado no Departamento Infanto-juvenil ou, posteriormente, no Adulto, ou ainda, aqueles que concluíram o curso e não deram continuidade. Houve, também, alunos com dificuldades no aprendizado que, graças a seus esforços e à ajuda de seus professores, superaram esses obstáculos e seguiram nos estudos.

Esta heterogeneidade em sala de aula deve ser trabalhada no sentido de auxiliar a todos para que aprendam música, toquem um instrumento e que essa educação contribua na construção de suas vidas. Toda sala de aula é, por natureza, heterogênea, e para realizar um bom trabalho, reconhecem-se atitudes interdisciplinares que auxiliam na construção do ensino musical. No reconhecimento da diversidade em sala de aula, o diálogo impõe-se como instrumento adequado, auxiliando na transformação dos professores, que se abrem à troca e às diferenças.

Estabeleceu-se, pois, a parceria e com ela a afetividade pôde ser expressa no trabalho, pois o professor afetivo com seus alunos torna o ensino significativo, o que os mantém à vontade para perguntar, dirimir suas dúvidas e abrandar as inquietações.

Acredita-se que a afetividade do professor pode colaborar na formação da identidade do aluno, em sua autonomia e, também, na expressão de sua criatividade. Estas são as categorias interdisciplinares frequentemente presentes em sala de aula e que colaboram, musicalmente, com a formação dos alunos e, por meio delas, procura-se acolher a todos, em suas diferenças. Infelizmente, nem sempre todos se sentem acolhidos, pois, em educação, não se têm garantias absolutas de que as melhores intenções correspondem aos melhores resultados.
A interdisciplinaridade, como atitude na pesquisa, auxilia o professor frente a esses desafios, nas mudanças metodológicas necessárias para que suas práticas sejam adequadas às crianças e aos jovens.

Neste sentido, foi necessária uma atitude interdisciplinar, de perguntar, constantemente, por quê? E como levou a rever as práticas de ensino? Portanto, ao ser colocado frente às dificuldades de entendimento apresentadas pelos alunos, e, também, na atitude de se colocar como se fosse o próprio aluno, reconheceu-se a melhoria da qualidade das aulas pois, ao estudar música com Koellereutter (1990), questiona-se tudo nas diversas disciplinas visando à educação que se complementa, que se faz interdisciplinar

Desde 2000, há uma intensa busca de novas e melhores alternativas para que os alunos não se limitem à execução da obra de determinado compositor, mas que possam, também, desenvolver elementos de composição e, desta maneira, por em prática suas ideias, escrevendo as próprias obras. Para auxiliá-los nesse processo, pôde-se arranjar a obra de um compositor, trabalhar sua releitura, reescrever e recriar, permitindo a todos o exercício da análise do que se criou em conjunto.

Ao reger o Grupo Instrumental de Práticas e Arranjos (GIPA), uma pequena orquestra formada por alunos que tocam, estudam seus instrumentos e praticam há um ano, no mínimo, empenhou-se em discutir os arranjos feitos, muitas vezes com os alunos, que colaboram com suas sugestões sempre bem-vindas. Exemplo disso são as alterações realizadas na forma da música: partes que serão, ou não, repetidas; a repetição, ou não, da música inteira; a alteração da introdução; o uso de determinada articulação para os violinos; a decisão em dobrar a melodia com a participação de outros instrumentos 
para que ela seja ouvida; e outras ideias vindas dos alunos que são sempre acolhidas e experimentadas para que a aprendizagem se concretize oferecendo-lhes a possibilidade de vivenciar a criatividade, a estética, a parceria e o diálogo.

É possível executar determinado trecho musical e depois experimentar outra maneira, conforme sugestão de um aluno, seguindo-se a sugestão de outro, comparando e resolvendo juntos quanto à melhor forma. A escolha é da maioria e, normalmente, todos ficam satisfeitos. Criam-se vínculo e parceria. A opinião de todos é devidamente considerada, buscando equilibrar o arranjo tanto estética quanto instrumentalmente.

A concentração nos diversos aspectos da obra que estão tocando torna os alunos participativos e criativos, por compreenderem não apenas a sua parte, mas o todo orquestral e, assim, cada parcela de contribuição faz a obra tomar um rumo que, no começo dos ensaios não tem clareza, como é natural, porém, aos poucos, ganha nitidez aos olhos do grupo. A soma dos esforços de cada um, de cada melodia, de cada instrumento com seu timbre próprio oferecem uma nova forma, um novo sentimento que passa a ser compartilhado por todos. A obra revela-se como tem sido acompanhado pelo professor em sua atuação diária.

Ao refazer a prática docente, é possível apropriar-se de uma nova maneira de atuar em sala de aula, tornando-se menos teórico, partindo do tocar em conjunto, do vivenciar em grupo para depois refletir e teorizar sobre o que se estava fazendo, o que a teoria dizia e como se pode entendê-la, no contexto apresentado.

O trabalho extraclasse foi realizado, pois a aula, com tempo escasso, regulando um processo criativo que, muitas vezes, depende de um tempo interno inverso ao cro- nológico, compeliu o aluno a compor em sua casa, experimentando suas ideias no instrumento, registrando na partitura. Ao corrigir a escrita musical de cada um para que todos tocassem em conjunto foi possível observar e aprender juntos as regras da grafia musical como prática de escrita para o aluno compositor.

Segundo Goulart (S.d.), a opção pelo instrumental Orff, ${ }^{1}$ em 2002, serviu de meio para criação de improvisos, de treino das mãos com as baquetas e ouvir uns aos outros, no improviso solo/"tutti”. Quando um aluno está solando, criando sua melodia -solo - os demais - "tutti" - acompanham de maneira bastante suave para que o solo seja ouvido. É gratificante observar que todos querem solar e ser ouvidos pelos demais. No entanto, nem sempre o contrário ocorre. É necessário que o docente entre em cena para explicar que se desejam para si, devem oferecer, também, aos outros.

Normalmente, quando da realização de exercícios, deve haver preocupação de se certificar que os alunos entendam os conceitos apresentados. Para aqueles que apresentam dificuldades, solicita-se que venham para a lousa, no papel de colaborador do professor, para resolver os exercícios. $\mathrm{O}$ aluno, portanto, tem a oportunidade de resolver problemas e ser ajudado pelos colegas da classe e, com isso, quem não encontra dificuldades, auxilia os demais. Durante os exercícios, solicitam-se respostas dos alunos com dificuldades e, também, dos desatentos. A classe presta atenção porque sabe que pode ser chamado, a qualquer momento, à participação.

\footnotetext{
${ }^{1} \mathrm{O}$ método de ensino da música para crianças proposto por Carl Orff em "Schulwerk Music for Children" (1930-33) começa com padrões rítmicos simples e progride até as peças complexas para conjuntos de xilofones, blocos de madeira, tambores e outros instrumentos de percussão.
} 
Percebe-se que certos alunos - o primeiro grupo - não sabem como responder, mas, de fato entendem o que foi explicado. Então, são reforçados os conceitos. O solfejo, os ritmos e os conceitos são resolvidos de modo prático para que todos possam vivenciá-los e compreendê-los. Canta-se, fala-se ritmicam1ente e dialoga-se em clima descontraído. O caderno de cada aluno é constantemente observado, com vistas à escrita e às respostas. Os exercícios com erros, musicalmente mal-escritos, são refeitos em casa.

O professor identifica e conversa com os alunos que apresentam dificuldades. A depender do caso, conversa inclusive com os pais desses alunos, para que possam também auxiliar os filhos nos estudos. Conhecendo melhor essas crianças, o professor tem um novo olhar e pode refletir nas estratégias facilitadoras do aprendizado. As dificuldades desses alunos podem ter causas das mais variadas, como: econômicas; de percepção sonora; relação com os pais; desatenção, entre outras tantas. Portanto, cabe ao docente questionar sobre a forma de ajudá-los, musicalmente, para que seus estudos sejam efetivos, significativos e estimulantes em suas vidas. Outro questionamento tem relação com a possibilidade de se criar uma ponte com o ensino regular que seus alunos frequentam e de acrescentar as qualidades inerentes à música para enriquecer esse ensino.

No crescimento musical dos alunos com dificuldades, observa-se que o professor, atento às suas necessidades de aprendizado, pode ajudar os alunos e, certamente, o quadro poderá se reverter, melhorando sensivelmente. Mais uma vez a afetividade estabelecida no trabalho cria oportunidades para o crescimento interior dos alunos. Eles passam a responder com mais segurança aos desafios propostos pelos professores, ampliando os conteúdos e as novas oportunidades de ensino e aprendizagem.
Um segundo tipo de alunos que se percebe é o que procura a Universidade Livre de Música (ULM) em busca de um aprendizado musical para suas vidas. Neste sentido, observa-se que boa parte será musicalizada, mas não dará continuidade aos estudos musicais. Há alunos que ficam na escola por quatro ou cinco anos e desistem. Acredita-se, entretanto, que tenham obtido bagagem musical que, provavelmente, contribuirá para outros fazeres em suas vidas, tornando-as mais belas, sensíveis e com percepção mais aflorada.

Muitos alunos reportam que o aprendizado musical contribuiu para que sejam bem-sucedidos em suas áreas de trabalho. Formam um público seleto, conhecedor, apreciador e divulgador da música de qualidade.

O terceiro tipo são os alunos talentosos, exímios instrumentistas em seus diversos níveis e com excelente criatividade para realizar performances musicais. Observam-se vários pré-adolescentes autodidatas em composição que vão à escola, mostram seus trabalhos composicionais, para instrumento solista, pequena formação ou até mesmo pequena orquestra. São alunos atentos e irrequietos, cuja intenção é o aprendizado, interessados sempre em extrair o máximo de seus professores. São respeitosos para com os mestres e sempre estão cursando novas disciplinas, buscando conhecimentos sobre novos temas. Normalmente, encaminham-se para as faculdades de música ou buscam a possibilidade de estudo no exterior.

Ao desenvolver as práticas pedagógicas que lidam com as diferenças do aprendizado entre os alunos e com uma educação que não visa a somente formar músicos, mas que se amplia e enriquece a partir do aprendizado da música, percebe-se que, a cada dia, 
são elaboradas novas possibilidades didáticas e reflexões aprofundadas sobre o tema Educação Musical e seu papel na escola.

\section{Considerações finais}

As mudanças vivenciadas nas diferentes gestões e os impactos dessas mudanças favoreceram o aprendizado dos docentes e os prepararam para as transformações em sala de aula. Se, com a primeira gestão, houve grande cumplicidade gerando sentimento de pertencimento e, portanto, de parceira e diálogo, com a segunda, o grupo foi obrigado a rever a própria prática, instalando-se o conflito.

Mas a resistência, com a chegada da nova ordem, criou um espaço de luta, impondo aos docentes uma revisão das próprias ações. Muitos aspectos positivos foram experimentados com a mudança. Entre eles vale destacar a exigência da revisão do material didático composto na primeira gestão, o olhar mais atento ao aluno incorporando a ludicidade como metodologia de ensino e a liberdade de cada professor para seguir seu caminho metodológico.

Na terceira gestão, a cargo de docentes da própria instituição, novamente o trabalho em parceria foi a tônica das orientações e, agora, o corpo docente constitui-se de um grupo de professores amadurecidos e mais preparados para lidar adequadamente com as mudanças e acolhê-las como um momento especial para a inovação e criatividade no qual o velho pode ser revisto e interdisciplinarmente ser novo outra vez (FAZENDA, 1992).

Nas três gestões, o registro cotidiano da ação docente é feito regularmente e apesar dos enfoques administrativos diferentes a cada gestão o que se constatou foi a rique- za que tais registros trazem para a reflexão e autoconhecimento dos professores, além de servirem para acompanhar o desenvolvimento dos projetos pedagógicos propostos.

Destarte, cabe a lembrança de que se tornar um professor vivo, irrequieto e atuante, tem sido grande desafio, ao mesmo tempo em que há prazer em trabalhar o ensino da música numa classe, reconhecidamente, heterogênea. Essa heterogeneidade constitui fator de enriquecimento da atividade docente e permite que a rotina escolar transforme-se em possibilidades criativas através das quais se constrói a educação musical.

Procurou-se, portanto, auxiliar o aprendizado e propiciar, aos três tipos de alunos encontrados em sala, o devido encaminhamento. Ao perceber as três categorias, agrupadas, para facilitar a compreensão sobre suas características, verificou-se a sua permeabilidade, pois não há como afirmar, categoricamente, que alunos de uma categoria - os talentosos, por exemplo - terão sempre esse comportamento, e, de igual modo, os alunos com dificuldade no aprendizado melhoram, sensivelmente, em qualidade, tornando-se bons músicos.

Ao buscar meios e alternativas para que os aspectos dessa heterogeneidade fossem compreendidos e que, efetivamente, pudessem auxiliar a todos, percebeu-se que a análise dessas características poderia resultar em práticas, levando a incluí-las no trabalho de aprendizagem, tornando-as desafios para o desenvolvimento musical.

Conheceram-se alunos talentosos que gostam de música, porém, foram levados à Universidade e frequentaram curso totalmente diferente, afastando a hipótese da profissionalização na música. Por outro lado, houve alunos que apresentaram muitas dificuldades, mas que superaram seus obstáculos e passaram a viver a música. Além dessas situações, alguns alunos que, de início, não 
demonstravam qualquer afinidade com o assunto, acabaram frequentando curso superior em determinado instrumento. Os desfechos narrados demonstram certa imprudência quando se aventa a possibilidade de generalizar resultados ou de se precipitar nas conclusões sobre o percurso de cada aluno.

Portanto, ao se buscar compreensão quanto à heterogeneidade que se instala no grupo de alunos, propiciando diversos métodos musicais para a aprendizagem da música, reconhece-se, também, que a atitude acolhedora da interdisciplinaridade como categoria de ação possibilita uma docência mais atenta às questões do ensino e da aprendizagem.

A interdisciplinaridade impõe um novo relacionamento entre professor e aluno. O professor não é mais aquele que transmite conhecimento ao aluno, mas aquele que o auxilia na descoberta de como construir e apropriar-se dos conhecimentos necessários para uma ação consciente no mundo (HAAS, 2000, p. 122).

Acredita-se na colaboração relativamente à formação musical dos alunos e, com isto, colaborar, também, no aspecto formação, na sua plenitude, para, musicalmente, ou não, se tornarem cidadãos capazes de auxiliar a sociedade com a grandeza de seus talentos e contribuindo através de uma ação consciente no mundo e esteticamente bela.

A música e a educação musical por meio da sensibilidade, da beleza e da harmonia poderão, com auxílio de atitudes interdisciplinares, propiciar que a escola cante em uníssono a mesma canção quando for necessário mas também poderão ser cantadas muitas canções, fazendo da escola um espaço que possibilita e acolhe de modo democrático as diferenças, os talentos, crenças e conquistas.

\section{Referências}

ABBAGNANO, N. Dicionário de filosofia. 4. ed. São Paulo: Martins Fontes, 2000.

FAZENDA, I. C. A. Integração e interdisciplinaridade no ensino brasileiro. São Paulo: Loyola, 1992.

Interdisciplinaridade: um projeto em parceria. 4. ed. São Paulo: Loyola, 1999.

(Org.). Dicionário em construção: interdisciplinaridade. São Paulo: Cortez, 2002.

GIL, A. C. Como elaborar projetos de pesquisa. 3. ed. São Paulo: Atlas, 1995.

GOULART, D. Dalcroze, Orff, Suzuki e Kodály: semelhanças, diferenças, especificidades. [S.d.]. Disponível em: <http://www.dianagoulart.pro.br/texto_ dalcroze.php>. Acesso em: 2 jul. 2011.

HAAS, C. M. Ressignificando o papel do coordenador de curso: uma vivência interdisciplinar. In: QUELUZ, A.G. (Org.). Interdisciplinaridade: formação de profissionais da educação. São Paulo: Pioneira, 2000. p. 103-125.

JUSTINA, R. D. Parceria. In: FAZENDA, I.C.A. (Org.). Dicionário em construção: interdisciplinaridade. São Paulo: Cortez, 2001.

KOELLREUTTER, H. J. Terminologia de uma nova estética da música. Porto Alegre: Movimento, 1990.

MENÉNDEZ, N.Z. Parceria. In: FAZENDA, I.C.A. (Org.) Dicionário em construção: interdisciplinaridade. São Paulo: Cortez, 2001. p. 157-159.

MORI, O. L. Educação musical: uma abordagem interdisciplinar das práticas musicais para compreender a heterogeneidade em sala de aula. 2003. Dissertação (Mestrado em 
Educação) - Universidade Cidade de São Paulo (UNICID), São Paulo, 2003.

PAZ, E. A. Pedagogia musical brasileira no século $\mathrm{XX}$ : metodologias e tendências. Brasília: MusiMed, 2000.

SÃO PAULO (Estado). Decreto Estadual $\mathbf{n}^{\mathbf{0}}$. 30.551, de 3 de outubro de 1989 . Introduz disposições e modificações no Decreto $\mathrm{n}^{\circ}$ 20.955, de $1^{\circ}$. de junho de 1983, e dá outras providências. Disponível em: <http://perfil.sp.gov.br/site/legislacaoi. asp?atoid=19404>. Acesso em: 23 nov. 2002.

Decreto Estadual $n^{\circ}$. 46.506, de 21 de janeiro de 2002. Altera a sede e a denominação da Universidade Livre de Música "Tom Jobim - Maestro Antônio Carlos Brasileiro de Almeida Jobim” e dá providência correlata. Disponível em: <http://www.al.sp.gov.br/legislacao/norma. do?id=282\&ementa=S\#inicio $>$. Acesso em: 23 nov. 2002.

SNYDERS, G. A escola pode ensinar as alegrias da música? 3. ed. São Paulo: Cortez, 1997.

WECHSLER, S.M. A educação criativa: possibilidade para descobertas. In: CASTANHO, S.; CASTANHO, M.E. (Orgs.). Temas e textos em metodologia do ensino superior. Campinas/SP: Papirus, 2001. p. 158-171.

Enviado em: 03/04/2011

Aceito em: 19/08/2011 